\title{
SÉANCE DU 8 OCTOBRE 1909
}

\author{
PRÉSIDENCE DE M. ÉD. PRILLIEUX.
}

M. le Président a le regret d'informer les membres présents du décès de trois de nos confrères, MM. Abel Albert, Lombard-Dumas et Amblard, ce dernier, membre fondateur de la Société.

Il annonce ensuite trois nouvelles présentations.

\section{DONS FAITS A LA SOCIÉTE}

Bois (D.) et Gadeceau (E.), Les végétaux, leur rôle dans la vie quotidienne.

Bommer (Ch.) et Massart (J.), Les aspects de la végétation en Belgique. - Les districts littoraux et alluviaux par J. Massart.

Brockmann-Jerosch, Neu Fossilfunde aus dem Quartär und deren Bedeutung für die Auffassung.

Dop (P.) et Gautié, Manuel de technique botanique.

Fliche (P.), La Champagne crayeuse, élude de géographie botanigue.

Fyson (P.-F.), Some Experiments in the Hybridising of Indian Cottons.

Grecescu (Dim.). Suplement la Conspectul Florei romanier.

Gulia (G.), Intorno ad un nuovo habitat della Melitella pusilla Somm.

Kolderup Rosenwinge, The marine Algx of Denmark. Part. I.

Lapie (G.), Les divisions phytogéographiques de l'Algérie. jura.

- Les subdivisions phytogéographiques de la Kabylie et du Djur-

Lecomte (H.), Notulæ systematicæ. Tome I, fasc. 1.

Lignier (0.), Essai sur l'évolution morphologique du règne végétal.

Massart (Jean), Essai de géographie des districts littoraux et alluviaux de la Belgique.

Maxon (W.-R.), Studies of the tropical American Ferns.

Paris $\left(G^{\text {al }}\right)$, Muscinées de l'A sie orientale, $10^{\circ}$ article.

Péchoutre (F.), Biologie florale.

Sennen (Frère), Plantes d'Espagne (Années 1906 et 1907).

Warming (Eug.) et Vahl (M.), OEcology of Plants. Traduction de Percy Grosse et J.-B. Balfour. 
Willis (J.-C.), Agriculture in the tropics.

Annales de l'Institut national agronomique, $2^{\circ}$ série, t. VIII, fasc. 1. Sociélé d'Histoire naturelle d'Autun, $21^{\mathrm{e}}$ Bulletin.

Bulletin de la Socièté botanique des Deux-Sèvres (Société régionale), 1908-1909.

Annales de la Station limnologique de Besse, fasc. 2.

Real Sociedad Española de Historia natural, t. VI, Mém. 1 et 2.

- Boletin, juillet 1909.

Travaux du Musée botanique de l'Académie Impériale des Sciences de Saint-Pétersbourg, VI.

Botanical Közlemenyek.

New-York Agriculture Experiment Station. Bulletins 314-315 et Technical Bulletin $\mathrm{n}^{\circ} 9$.

Miscellaneous Papers (Contributions from the U. S. Botanical Herbarium), XII, 10.

Revista de la Facultad de Lettras y Ciencias (Universitad de la Habana), VI, 2 ; VIII, 1.

Bulletin du département de l'Agricultural aux Indes néerlandaises, XXIII.

The Philippine Journal of Science, vol. I-III.

Au nom de M. Ed. Bornet, empèché, M. Mangin donne lecture de la Notice suivante :

\title{
Maurice-Augustin Gomont (1839-1909);
}

\author{
PAR M. ÉD. BORNET.
}

Notre distingué confrère, M. GoMost, est mort à Rouen, le 22 juin, dans sa soixante et onzième année, enlevé subitement à l'affection de sa famille et de ses amis. Très lié avec M. Gomost depuis une trentaine d'années, ayant provoqué et suivi ses travaux sur les Algues, j'ai plus qu'un autre le devoir mélancolique de rappeler ici ce qu'il fut et ce qu'il a fait.

Maurice-Augustin Gomont est né à Rouen le 11 mai 1839. Il descendait d'une ancienne famille normande comptant parmi ses membres nombre de littérateurs et d'érudits. Son père, Henri Gomost, a publié des traductions d'auteurs latins et anglais et des ouvrages en prose et en vers. On doit à son oncle de Fréville, de l'École des Chartes, des ouvrages d'archéologie. Sa mère avait un talent de peintre fort agréable.

Il fit de brillantes études au Collège Bonaparte où il fut le condisciple de Sully Prudhonme, de Sadi Carsot, de l'abbé Odelis, d'Albert de 


\section{$2 \mathrm{BHL}$ Biodiversity Heritage Library}

1909. "Séance Du 8 Octobre 1909." Bulletin de la Société botanique de France 56, 439-440. https://doi.org/10.1080/00378941.1909.10832077.

View This Item Online: https://www.biodiversitylibrary.org/item/8678

DOI: https://doi.org/10.1080/00378941.1909.10832077

Permalink: https://www.biodiversitylibrary.org/partpdf/160812

\section{Holding Institution}

Missouri Botanical Garden, Peter H. Raven Library

\section{Sponsored by}

Missouri Botanical Garden

\section{Copyright \& Reuse}

Copyright Status: Public domain. The BHL considers that this work is no longer under copyright protection.

This document was created from content at the Biodiversity Heritage Library, the world's largest open access digital library for biodiversity literature and archives. Visit BHL at https://www.biodiversitylibrary.org. 